\title{
THE EFFECTIVENESS OF ACTIVE SHIELDING OF MAGNETIC FIELD WITH CIRCULAR SPACE-TIME CHARACTERISTIC AND WITH DIFFERENT SHIELDING COILS SPATIAL POSITIONS
}

Aim. The synthesis, computer modeling and field experimental research of two degree of freedom robust two circuit system of active shielding of magnetic field with circular space-time characteristic, generated by overhead power lines with "triangle» type of phase conductors arrangements and with different shielding coils spatial positions for reducing the magnetic flux density to the sanitary standards level and to reducing the sensitivity of the system to plant parameters uncertainty. Methodology. The synthesis is based on the multi-criteria game decision, in which the payoff vector is calculated on the basis of the Maxwell equations quasi-stationary approximation solutions. The game decision is based on the stochastic particles multiswarm optimization algorithms. The initial parameters for the synthesis by system of active shielding are the location of the overhead power lines with respect to the shielding space, geometry and number of shielding coils, operating currents, as well as the size of the shielding space and magnetic flux density normative value, which should be achieved as a result of shielding. The objective of the synthesis is to determine their number, configuration, spatial arrangement and shielding coils currents, the control systems parameters as well as the resulting of the magnetic flux density value at the shielding space. Results. Computer simulation and field experimental research results of two degree of freedom robust two circuit system of active shielding of magnetic field, generated by overhead power lines with «triangle» type of phase conductors arrangements and with different shielding coils spatial positions are given. The possibility of initial magnetic flux density level reducing and system sensitivity to the plant parameters uncertainty reducing is shown. Originality. For the first time the synthesis, theoretical and experimental research of two degree of freedom robust two -circuit t system of active shielding of magnetic field generated by single-circuit overhead power line with phase conductor's triangular arrangements and with different shielding coils spatial positions carried out. Practical value. Practical recommendations from the point of view of the practical implementation on reasonable choice of the spatial arrangement of two shielding coils of robust two -circuit system of active shielding of the magnetic field with circular space-time characteristic generated by single-circuit overhead power line with phase conductor's triangular arrangements are given. References 32, figures 20.

Key words: overhead power lines with «triangle» type of phase conductors arrangements, magnetic field, system of active shielding, computer simulation, field experimental research.

Цель. Синтез, компьютерное моделирование и полевые экспериментальные исследования комбинированной робастной двухконтурной системы активного экранирования магнитного поля с круговой пространственновременной характеристикой, генерируемого одноконтурной воздушной линией электропередачи с треугольным подвесом проводов, и с различным пространственным расположением экранирующих обмоток для снижения индукции магнитного поля до уровня санитарных норм и для снижсения чувствительности системы к неопределенности параметров объекта управления. Методология. Синтез основан на решении многокритериальной стохастической игры, в которой векторный выцгрыш вычисляется на основании решений уравнений Максвелла в квазистационарном приближении. Рещение игры находится на основе алгоритмов стохастической мультиагентной оптимизации мультироем частиц. Исходными параметрами для синтеза системы активного экранирования являются расположсение высоковольтной линий электропередачи по отношению к экранируемому пространству, ее геометрические размеры, количество проводов и рабочие токи линии электропередачи, размеры экранируемого пространства и нормативное значение индукции магнитного поля, которое долэно быть достигнуто в результате экранирования. Задачей синтеза является определение количества, конфигурации, пространственного расположения и значения токов в экранирующих обмотках, параметры системы управления, а также результирующего значения индукции магнитного поля в экранируемом пространстве. Результаты. Приводятся результаты компьютерного моделирования и полевых экспериментальных исследований комбинированной робастной двухконтурной системы активного экранирования магнитного поля, генерируемого воздуиной линией электропередачи с треугольным подвесом проводов, $и$ с различным пространственным расположением экранирующих обмоток. Показана возможность снижения уровня индукции исходного магнитного поля внутри экранируемого пространства и снижения чувствительности системы к неопределенностям параметров объекта управления. Оригинальность. Виервые проведены синтез, теоретические и экспериментальные исследования комбинированной робастной двухконтурной системы активного экранирования магнитного поля, генерируемого одноконтурной воздушной линией электропередачи с треугольным подвесом проводов. Практическая ценность. Приводятся практические рекомендации по обоснованному выбору с точки зрения практической реализации пространственного расположения двух экранирующих обмоток двухконтурной робастной системы активного экранирования магнитного поля с круговой пространственно-временной характеристикой, создаваемого одноконтурной воздушной линией электропередачи с треугольным подвесом проводов. Библ. 32, рис. 20.

Ключевые слова: воздушная линия электропередач, подвес проводов типа «треугольник», магнитное поле, система активного экранирования, компьютерное моделирование, полевые экспериментальные исследования.

Introduction. World Health Organization experts have identified the carcinogenic properties of the power frequency (PF) magnetic field (MF). Therefore, in the world over the past 15 years, sanitary standards are constantly tightening at the maximum permissible level of $\mathrm{MF}$ induction of $50-60 \mathrm{~Hz}$ and intensive research is being conducted on the development of methods for MF normalization. Overhead power lines (OPL) are one of the most dangerous for people sources of PF MF [1, 2].

Active contour shielding of PF MF generated by OPL $[3,4]$ is the most acceptable and economically (c) B.I. Kuznetsov, T.B. Nikitina, I.V. Bovdui 
feasible for ensuring the sanitary norms of Ukraine in the PF MF. The methods of synthesis of systems of active shielding (SAS) for MF, generate by OPL, developed in [5-8].

Single-circuit SAS with single SC is most widely used in world practice [3]. Such SAS can effectively shielded by MF with a small polarization. The space-time characteristics (STC) of such MF is a very elongated ellipse whose ellipse coefficient (ratio of the smaller axis to the larger axis) is seeks to zero. Single SC of singlecircuit OPL generates MF, whose STC is a straight line. With such a single- circuit SAS with single SC, the major axis of the STS ellipse of the initial MF is compensated, so that the STS of the total MP with SAS is on is significantly smaller than the STS of the initial MF, which determines the high shielding factor of such singlecircuit SAS. Single-circuit OPL with horizontal and vertical bus arrangement, double-circuit OPL such as «barrel», «tree» and «inverted tree», and groups of OPL generates a MF with a weak polarization.

However, the single-circuit OPL with phase conductor's triangular arrangements generated most polarized MF. The STC of such MF is practically a circle. Therefore, for effective shielding of such MF it is necessary to have two SC at least [5]. Note that the vast majority of single-circuit OPL in Ukraine has just such phase conductors triangular arrangements.

The goal of this work is the synthesis, computer modeling and field experimental research of two degree of freedom robust two circuit system with different both shielding coils spatial positions for active shielding of magnetic field with circular space-time characteristic, generated by overhead power lines with «triangle» type of phase conductors arrangements for reducing the magnetic flux density to the sanitary standards level and to reducing the sensitivity of the system to plant parameters uncertainty.

Problem statement. The initial data for the synthesis of the SAS are the parameters of the transmission lines (working currents, geometry and number of wires, location of the transmission lines relative to the protected space) and the dimensions of the shielding space and magnetic flux density sanitary standards level, which should be achieved as a result of shielding [12-22]. In the process of synthesis, it is necessary to determine the parameters of the shielding coils (SC) (their number, configuration, and spatial arrangement), currents and the resulting magnetic flux density level. To shielding factor improvement two degree of freedom SAS are used in which simultaneously used feed back regulator for closed loop control and feed forward regulator for open loop control [22-26].

Two degree of freedom robust SAS synthesizing problem reduced $[27,28]$ to the determination of such SC spatial arrangement and geometric sizes, as well as parameters of the regulator vector and uncertainty parameters vector, which the maximum value of the magnetic flux density in the shielding space points assumes a minimum value for the SC spatial arrangement and geometric sizes parameters vector but the maximum value for the uncertainty parameters vector [28]. The two degree of freedom robust SAS includes open loop and closed loop control. The synthesis of such two degree of freedom robust SAS is based on the multi-criteria game decision [29-31], in which the payoff vector calculated on the basis of the Maxwell equations quasi-stationary approximation solutions $[1,2]$. The game decision based on the stochastic particles multiswarm optimization algorithms [32].

Computer simulation results. Consider the results of the two degree of freedom robust two circuit SAS synthesis of MF with circular space-time characteristic generated by $110 \mathrm{kV}$ OPL with triangular conductors arrangement in a single-story building located at a distance of $10 \mathrm{~m}$ from OPL. In Fig. 1 are shown location of OPL and shielding space (SS) in which MF must mitigated to the sanitary norms level. In Figure 1 also are shown location of both SC. SC upper parts are coordinates $(3.0416,3.4965)$ and $(7.1943,3.6818)$. SC lower parts are coordinates $(6.3707,0.6637)$ and $(2.8478$, 2.4522).

At 250 A OPL current, its necessary 86.2448 and 86.2768 amperes of turns (AT) in SC. Phase current shifts are $0.8074 \mathrm{rad}$ and $1.2043 \mathrm{rad}$.

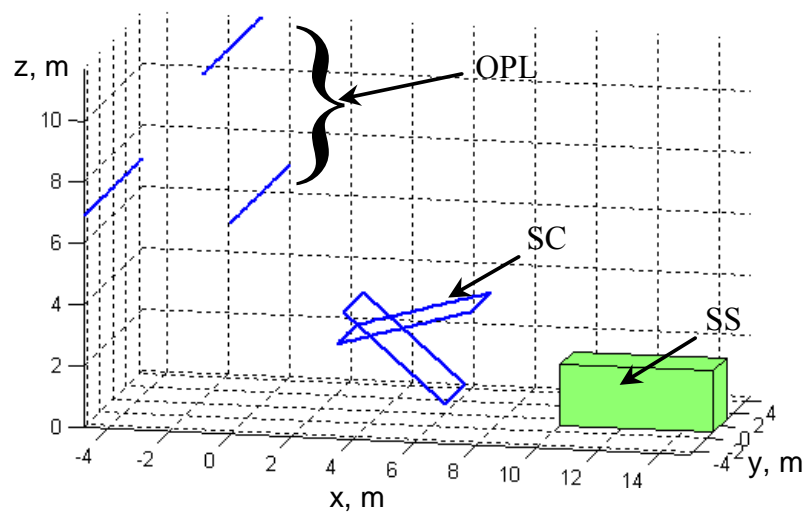

Fig. 1. The location of $110 \mathrm{kV}$ overhead power line with phase conductors triangular arrangements, both shielding coils and shielding space

In Figure 2 are shown comparison of magnetic flux density between working SAS with and without SAS. The initial magnetic flux density level in shielding space is $0.75 \mu \mathrm{T}$. When the SAS is on, the magnetic flux density level in shielding space is reduced to $0.12 \mu \mathrm{T}$. Therefore, the shielding factor is 6.25 .

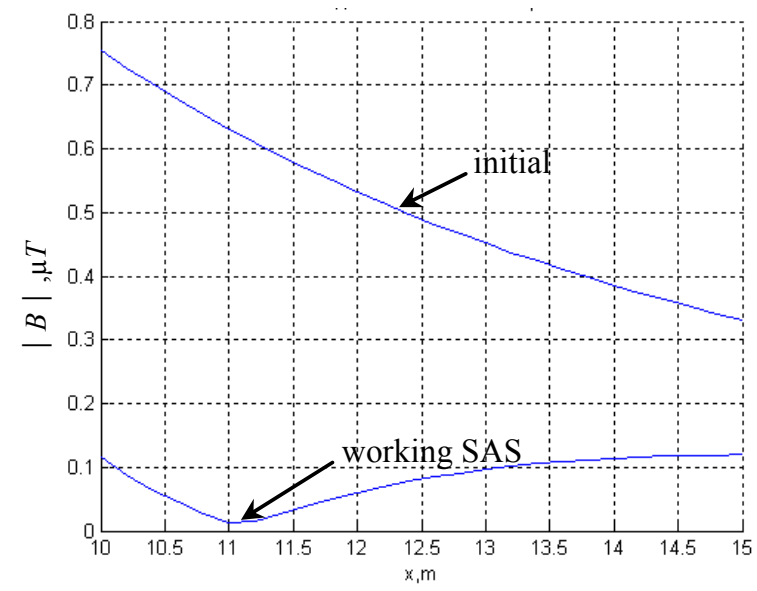

Fig. 2. Comparison of magnetic flux density between with and without system of active shielding 
In Figure 3 are shown the MF STC, generated by OPL (1); both SC (2) and total MF with SAS is on (3). The STC of initial MF generated by OPL with phase conductors triangular arrangements close to the circle. STC of MF generated by both SC is also close to the circle of the STC of initial MF, which ensures high shielding factor.

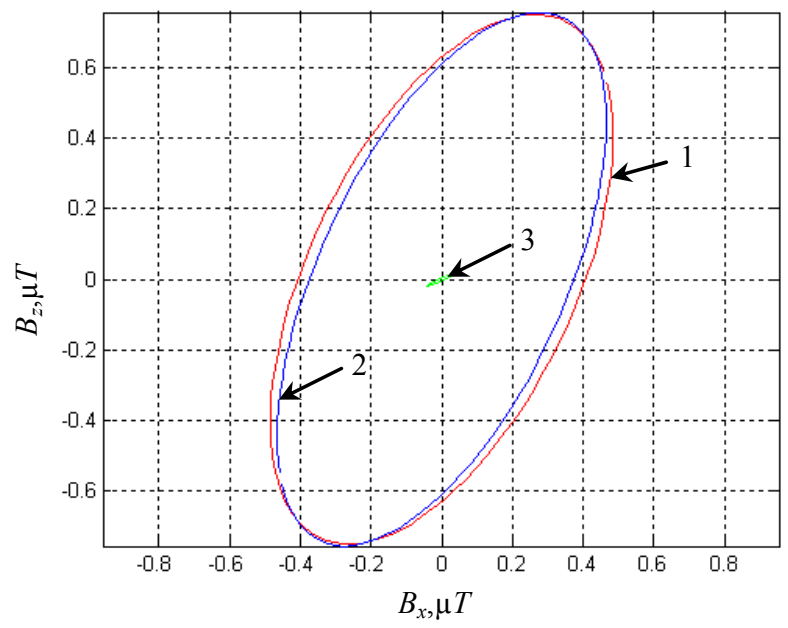

Fig. 3. Comparison of space-time characteristics of magnetic flux density between with and without system of active shielding and both shielding coils

However, STC of MF generated separately by only single first SC or only single second SC are straight lines. Naturally, the STC of the resulting MF generated by OPL and only single SC is an ellipse, which will be shielded by another SC. In Figure 4 are shown the STC of the initial MF generated by OPL, shielding MF generated by only single first SC and the resulting MF when only single first $\mathrm{SC}$ is used.

As can seen from Fig. 4, the STC of the resulting $\mathrm{MF}$ is a strongly elongated ellipse, the semi-major axis of which is almost two times larger than the STC of the initial MF, and therefore, due to only single first SC work, initial MF is almost twice re compensated.

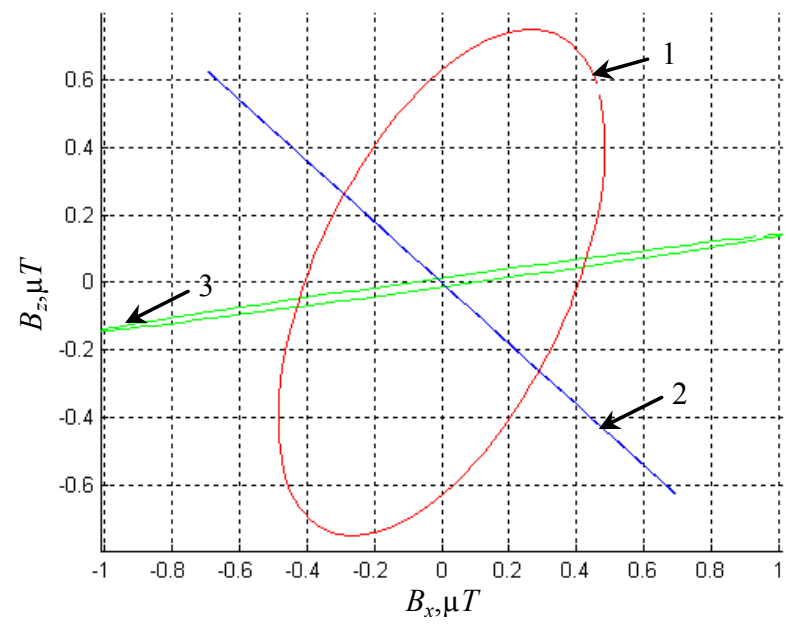

Fig. 4. Comparison between space-time characteristics of magnetic flux density without and with system of active shielding with only single first shielding coil and only single first shielding coil

However, then after second SC switching resulting MF STC becomes significantly less than the STC of initial MF, which ensures high shielding factor. Note that the STC of the resulting MF, left after the operation of only single first SC, practically parallel with the STC generated by the MF using only single second SC.

In Figure 5 are shown the STC of the initial MF generated by OPL, shielding MF generated by only single second $\mathrm{SC}$ and the resulting MF when only single second $\mathrm{SC}$ is used.

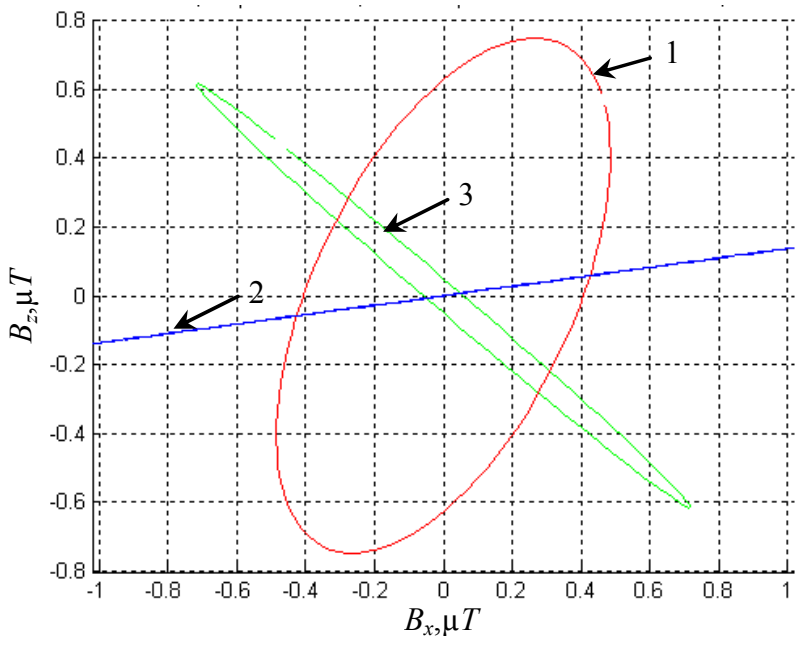

Fig. 5. Comparison between space-time characteristics of magnetic flux density without and with system of active shielding with only single second shielding coil and only single second shielding coil

As can seen from Fig. 4 and Fig. 5, STC of MF generated separately by only single first $\mathrm{SC}$, or only single second SC are straight lines. However, STC of the resulting $\mathrm{MF}$, which left after the operation of only single first (or second) SC, practically parallel with the MF STC of $\mathrm{MF}$, generated by using only single second (or first) SC. It is the STC arrangement that provides ensures high shielding factor, when both SC work simultaneously.

Notice, that the initial magnetic flux density level ranges from $0.75 \mu \mathrm{T}$ to $0.35 \mu \mathrm{T}$ in all shielding space, as can be seen from Fig. 2. When SAS is on, the magnetic flux density level does not exceed $0.12 \mu \mathrm{T}$ in all shielding space, as can be seen from Fig. 2.

However, when SAS is on and with only single first $\mathrm{SC}$ is used, the magnetic flux density level ranges from $1.5 \mu \mathrm{T}$ to $0.3 \mu \mathrm{T}$ in all shielding space. Consequently, when SAS is on and with only single first SC is used initial magnetic flux density level more than double due to overcompensation.

However, when SAS is on and with only single second $\mathrm{SC}$ is used, the magnetic flux density level ranges from $2 \mu \mathrm{T}$ to $0.4 \mu \mathrm{T}$ in all shielding space. Consequently, when SAS is on and with only single second SC is used initial magnetic flux density level also more than 2.5 due to recompensation. However, when SAS is on and with both first SC and second SC is used, the magnetic flux density level does not exceed $0.12 \mu \mathrm{T}$ in all shielding space. Consequently, when SAS is on and with both first $\mathrm{SC}$ and second SC is used shielding factor is 6.25 .

Notice also, that initial magnetic flux density level overcompensation effect with only single first SC also follows from comparison between MF STC without and with SAS with only single first SC. Similarly initial 
magnetic flux density level overcompensation effect with only single second SC also follows from comparison between MF STC without and with SAS with only single second SC.

Magnetic flux density level sanitary norms of Ukraine are $0.5 \mu \mathrm{T}$. When the SAS is on, the magnetic flux density level in shielding space is reduced to $0.12 \mu \mathrm{T}$ at 250 A OPL current. Consider the results of the SAS synthesis at $700 \mathrm{~A}$ OPL current. In Fig. 6 are shown location of OPL and shielding space in which MF must mitigated to the sanitary norms level and location of both SC. SC upper parts are coordinates $(2,4)$ and $(6,3.1031)$. The SC lower parts are coordinates $(6.6897,1.5394)$ and $(2,0)$.

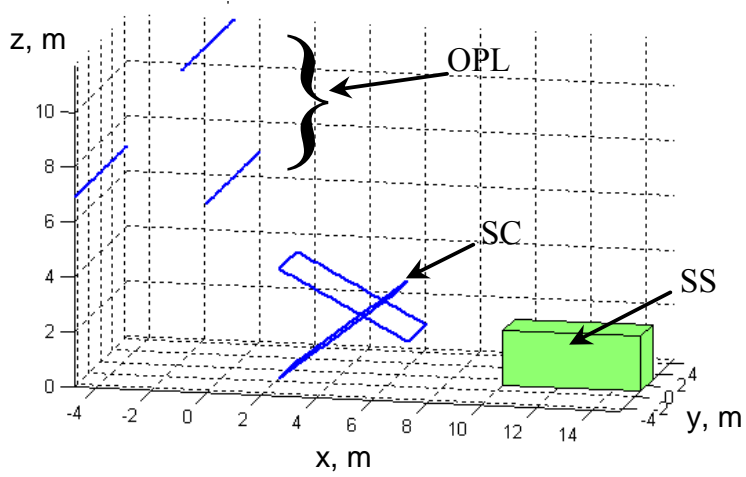

Fig. 6. The location of $110 \mathrm{kV}$ overhead power line with phase conductors triangular arrangements, both shielding coils and shielding space

At 750 A OPL current, its necessary 158.9729 and -178.5417 AT in SC. Phase Current Shifts are 0.6934 rad and 1.5959 rad. In Figure 7 are shown comparison of magnetic flux density between with and without SAS. The initial magnetic flux density level in shielding space is $2.25 \mu \mathrm{T}$. When the SAS is on, the magnetic flux density level in shielding space is reduced to $0.55 \mu \mathrm{T}$. Therefore, the shielding factor is 4.1 .

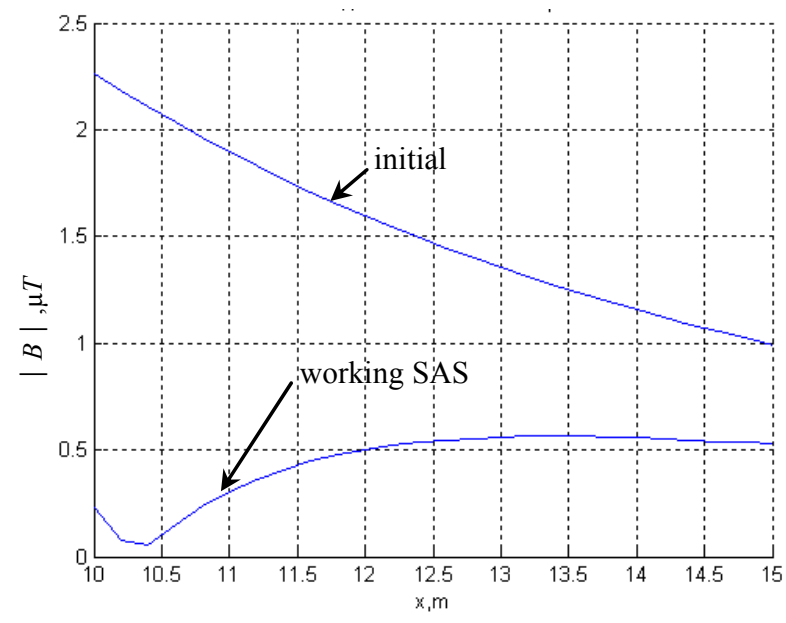

Fig. 7. Comparison of magnetic flux density between with and without system of active shielding

In Figure 8 are shown the MF STC, generated by OPL (1); both SC (2) and total MF with SAS is on (3).

The STC of initial MF generated by OPL with phase conductors triangular arrangements close to the circle. STC of MF generated by both SC is also close to the circle of the STC of initial MF, which ensures high shielding factor.

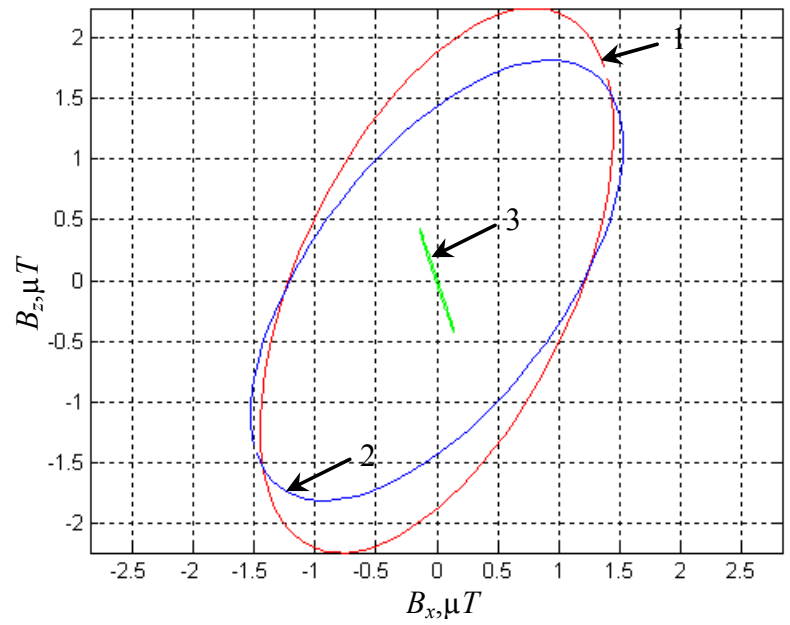

Fig. 8. Comparison of space-time characteristics of magnetic flux density between with and without system of active shielding and both shielding coils

The STC of the resulting MF generated by OPL and only single $\mathrm{SC}$ is an ellipse, which will be shielded by another SC. In Figure 9 are shown the STC of the initial MF generated by OPL, shielding MF generated by only single first $\mathrm{SC}$ and the resulting MF when only single first $\mathrm{SC}$ is used. The STC of the resulting MF is a strongly elongated ellipse, the semi-major axis of which is almost two times larger than the STC of the initial MF, and therefore, due to only single first SC work, initial MF is almost twice re compensated. However, then after second SC switching resulting MF STC becomes significantly less than the STC of initial MF, which ensures high shielding factor. Note that the STC of the resulting MF, left after the operation of only single first SC, practically parallel with the STC generated by the MF using only single second SC.

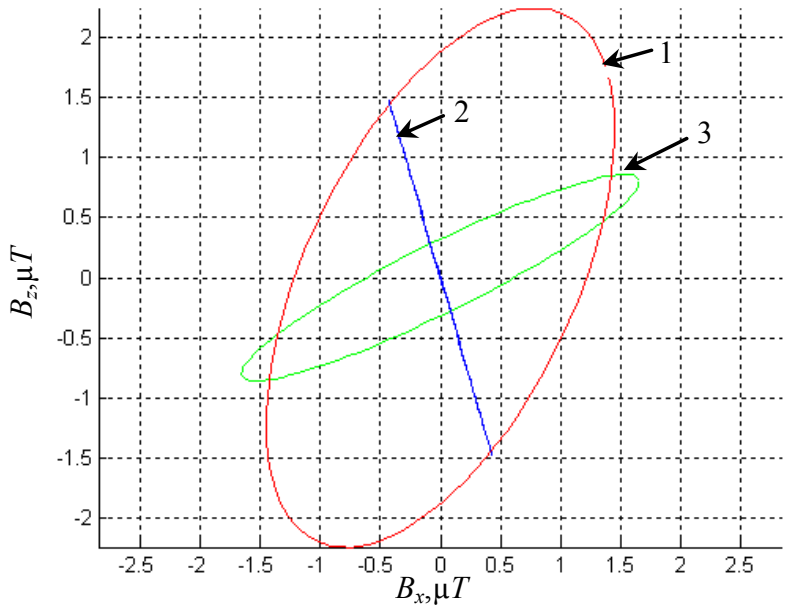

Fig. 9. Comparison between space-time characteristics of magnetic flux density without and with system of active shielding with only single first shielding coil and only single first shielding coil

In Figure 10 are shown the STC of the initial MF generated by OPL, shielding MF generated by only single second SC and the resulting MF when only single second $\mathrm{SC}$ is used. 


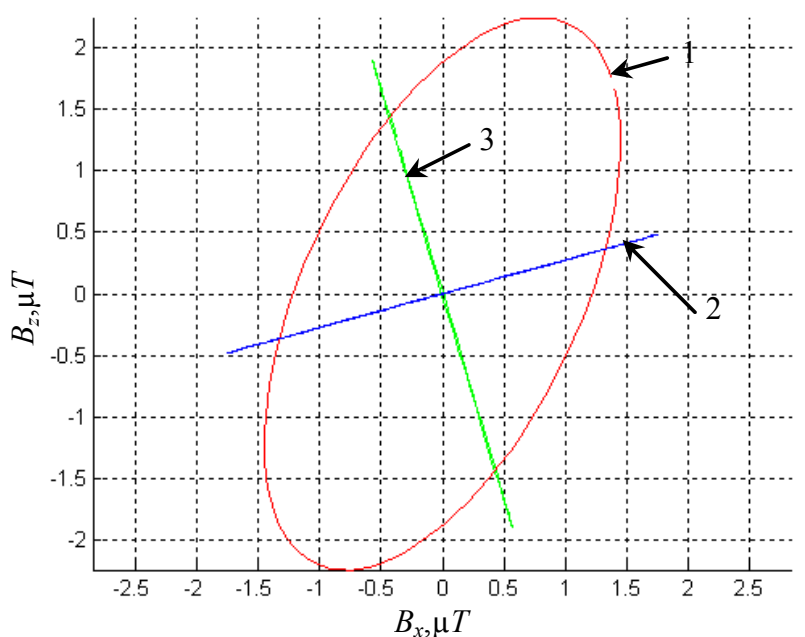

Fig. 10. Comparison between space-time characteristics of magnetic flux density without and with system of active shielding with only single second shielding coil and only single second shielding coil

The initial magnetic flux density level ranges from $2.25 \mu \mathrm{T}$ to $1 \mu \mathrm{T}$ in all shielding space, as can be seen from Fig. 7. However, when SAS is on and with only single first SC is used, the magnetic flux density level ranges from $2 \mu \mathrm{T}$ to $0.8 \mu \mathrm{T}$ in all shielding space. When SAS is on and with only single second SC is used, the magnetic flux density level ranges from $3.5 \mu \mathrm{T}$ to $1.2 \mu \mathrm{T}$ in all shielding space. Consequently, when SAS is on and with only single second SC is used initial magnetic flux density level also more than 1.5 due to recompensation. However, when SAS is on and with both first SC and second SC is used, the magnetic flux density level does not exceed $0.55 \mu \mathrm{T}$ in all shielding space. Consequently, when SAS is on and with both first SC and second SC is used shielding factor is 4.1.

At 750 A OPL current when the SAS is on the magnetic flux density level in shielding space is reduced to $0.55 \mu \mathrm{T}$, which exceeds the magnetic flux density level sanitary norms of Ukraine is $0.5 \mu \mathrm{T}$. So consider the results of the SAS synthesis at 625 A OPL current. In Fig. 11 are shown location of OPL and shielding space in which MF must mitigated to the sanitary norms level and location of both SC. SC upper parts are coordinates $(8.544,2.6895)$ and $(3.069,2.8128)$. SC lower parts are coordinates $(4.8693,0.1461)$ and $(8.4686,0.2538)$. At 750 A OPL current, its necessary 77.5265 and -73.1804 AT in SC. Phase current shifts are $1.1091 \mathrm{rad}$ and $0.8583 \mathrm{rad}$.

In Figure 12 are shown comparison of magnetic flux density between with and without SAS. The initial magnetic flux density level in shielding space is $1.9 \mu \mathrm{T}$. When the SAS is on, the magnetic flux density level in shielding space is reduced to $0.4 \mu \mathrm{T}$. Therefore, the shielding factor is 4.75 .

In Figure 13 are shown the MF STC, generated by OPL (1); both SC (2) and total MF with SAS is on (3).

The STC of initial MF generated by OPL with phase conductors triangular arrangements close to the circle. STC of MF generated by both SC is also close to the circle of the STC of initial MF, which ensures high shielding factor.

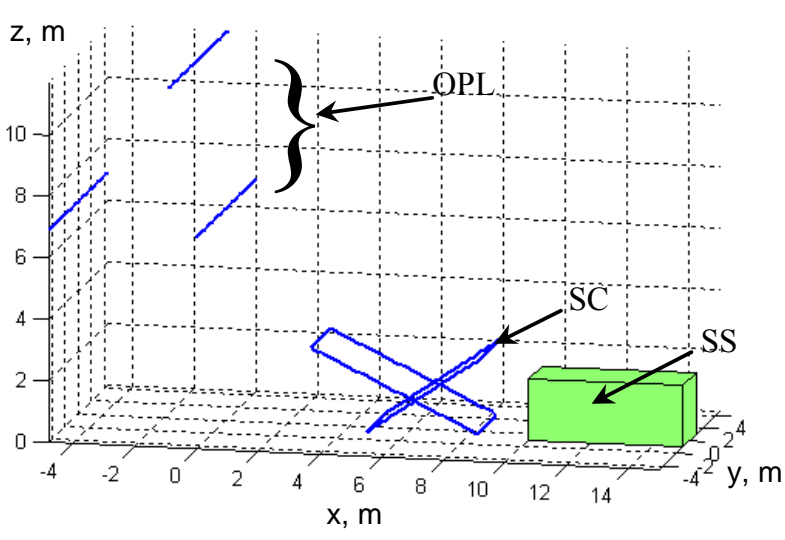

Fig. 11. The location of $110 \mathrm{kV}$ overhead power line with phase conductors triangular arrangements, both shielding coils and shielding space

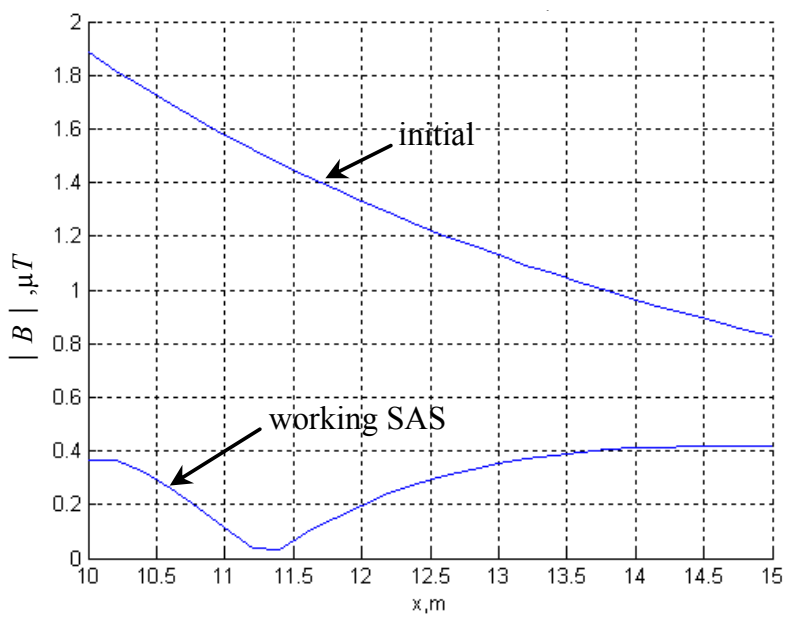

Fig. 12. Comparison of magnetic flux density between with and without system of active shielding

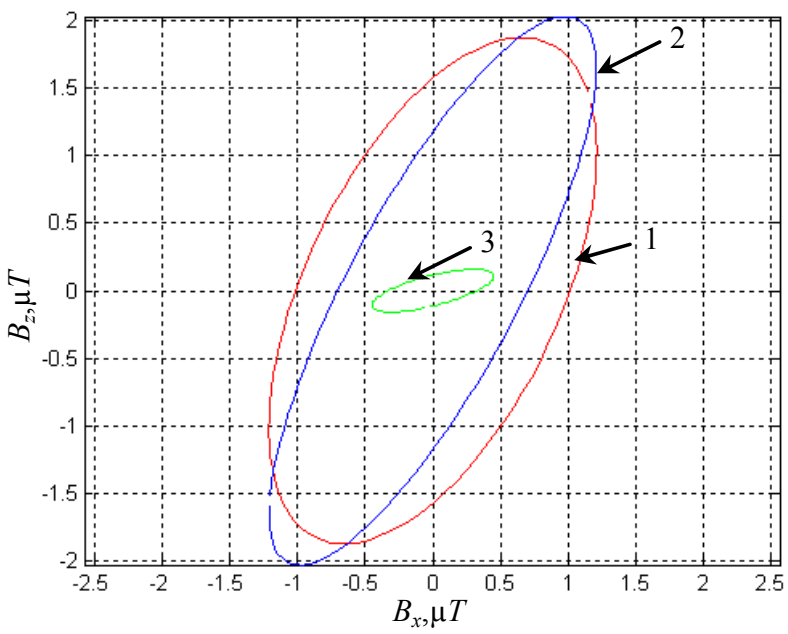

Fig. 13. Comparison of space-time characteristics of magnetic flux density between with and without system of active shielding and both shielding coils

The STC of the resulting MF generated by OPL and only single $\mathrm{SC}$ is an ellipse, which will be shielded by another SC. In Figure 14 are shown the STC of the initial MF generated by OPL, shielding MF generated by only single first $\mathrm{SC}$ and the resulting MF when only single first $\mathrm{SC}$ is used.

As can seen from Fig. 14, the STC of the resulting $\mathrm{MF}$ is a strongly elongated ellipse, the semi-major axis of 
which is almost two times larger than the STC of the initial MF, and therefore, due to only single first SC work, initial MF is almost twice re compensated. However, then after second SC switching resulting MF STC becomes significantly less than the STC of initial MF, which ensures high shielding factor. Note that the STC of the resulting MF, left after the operation of only single first $\mathrm{SC}$, practically parallel with the STC generated by the MF using only single second SC.

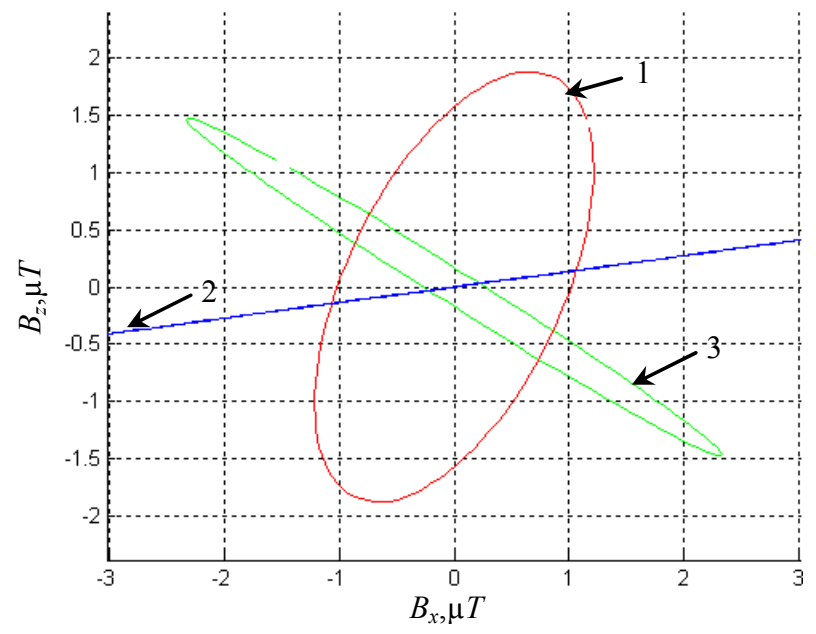

Fig. 14. Comparison between space-time characteristics of magnetic flux density without and with system of active shielding with only single first shielding coil and only single first shielding coil

In Figure 15 are shown the STC of the initial MF generated by OPL, shielding MF generated by only single second $\mathrm{SC}$ and the resulting $\mathrm{MF}$ when only single second $\mathrm{SC}$ is used.

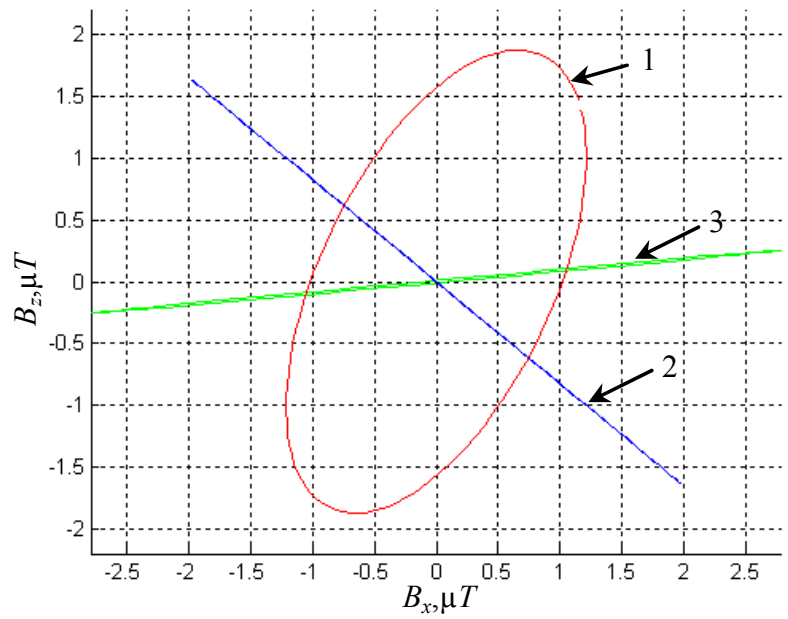

Fig. 15. Comparison between space-time characteristics of magnetic flux density without and with system of active shielding with only single second shielding coil and only single second shielding coil

At 625 A OPL current the initial magnetic flux density level ranges from $2 \mu \mathrm{T}$ to $0.9 \mu \mathrm{T}$ in all shielding space, as can be seen from Fig. 2. However, when SAS is on and with only single first SC is used, the magnetic flux density level ranges from $4 \mu \mathrm{T}$ to $0.7 \mu \mathrm{T}$ in all shielding space. Consequently, when SAS is on and with only single first SC is used initial magnetic flux density level more than double due to overcompensation.
However, when SAS is on and with only single second SC is used, the magnetic flux density level ranges from $5 \mu \mathrm{T}$ to $1 \mu \mathrm{T}$ in all shielding space. Consequently, when SAS is on and with only single second SC is used initial magnetic flux density level also more than double due to recompensation. However, when SAS is on and with both first SC and second SC is used, the magnetic flux density level does not exceed $0.4 \mu \mathrm{T}$ in all shielding space. Consequently, when SAS is on and with both first SC and second SC is used shielding factor is 4.75 .

The initial magnetic flux density level overcompensation effect with only single first SC also follows from comparison between MF STC without and with SAS with only single first SC, which Fig. 14 shows. Similarly initial magnetic flux density level overcompensation effect with only single second SC also follows from comparison between MF STC without and with SAS with only single second SC, which in Fig. 15 are shown.

To realize the SAS according to the first option of SC spatial arrangement which is shown in Fig. 1, even at a of 250 A OPL current, its necessary 86.2448 and 86.2768 AT in SC. Wherein SC upper parts are coordinates $(3.0416,3.4965)$ and $(7.1943,3.6818)$. SC lower parts are coordinates $(6.3707,0.6637)$ and $(2.8478$, 2.4522 ). To reduce the number of amperes in the SC, we bring the SC to the shielding space. Consider the results of the SAS synthesis at $250 A$ OPL current. In Fig. 16 are shown location of OPL and shielding space in which MF must mitigated to the sanitary norms level and location of both SC. The SC upper parts are coordinates (6.0278, 2.9014) and $(7.9925,3.1824)$. SC lower parts are coordinates $(8.0261,1.0391)$ and $(5.9751,0.1319)$.

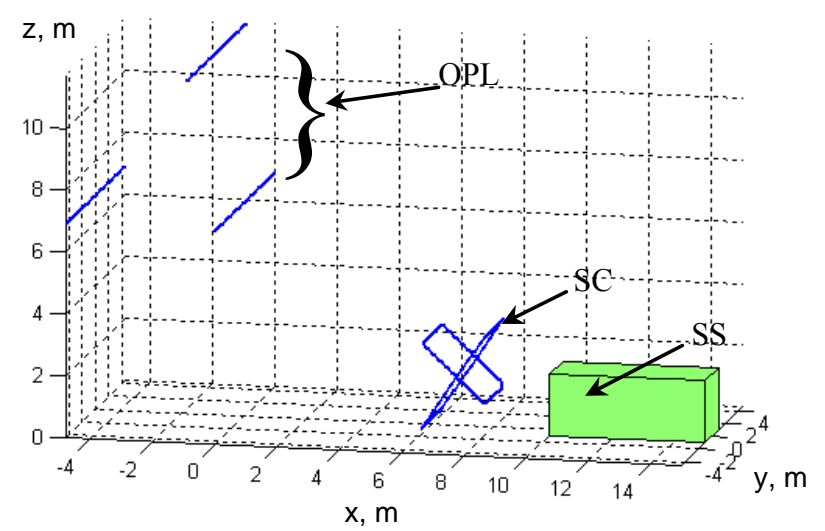

Fig.16. The location of $110 \mathrm{kV}$ overhead power line with phase conductors triangular arrangements, both shielding coils and shielding space

In this SAS at $250 \mathrm{~A}$ OPL current, its necessary 28.7127 and -25.6121 AT in SC. Phase current shifts are $1.0056 \mathrm{rad}$ and $1.6681 \mathrm{rad}$. In Figure 17 are shown comparison of magnetic flux density between with and without SAS. The initial magnetic flux density level in shielding space is $0.75 \mu \mathrm{T}$. When the SAS is on, the magnetic flux density level in shielding space is reduced to $0.26 \mu \mathrm{T}$. Therefore, the shielding factor is 2.88 . 


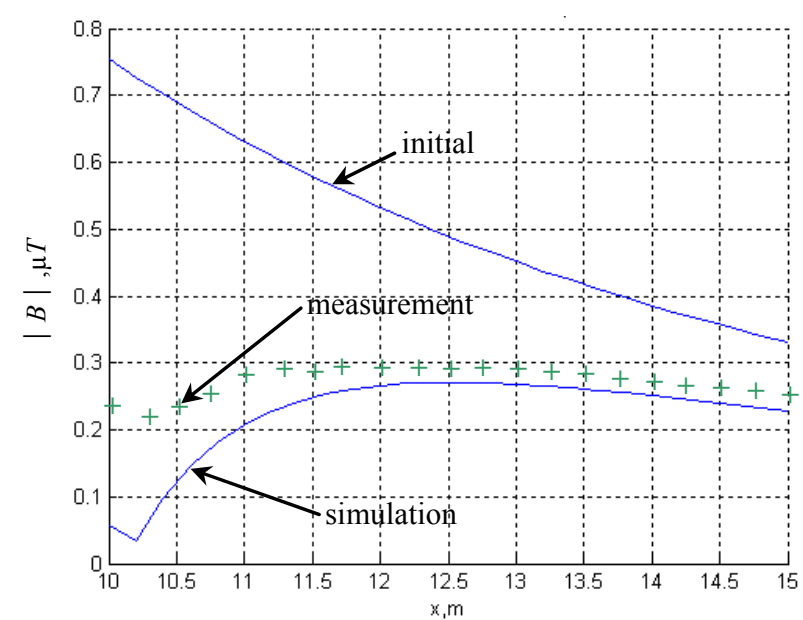

Fig. 17. Comparison of magnetic flux density between measurements and simulations with and without system of active shielding

In Figure 18 are shown the STC of MF, generated by OPL (1); both SC (2) and total MF with SAS is on (3).

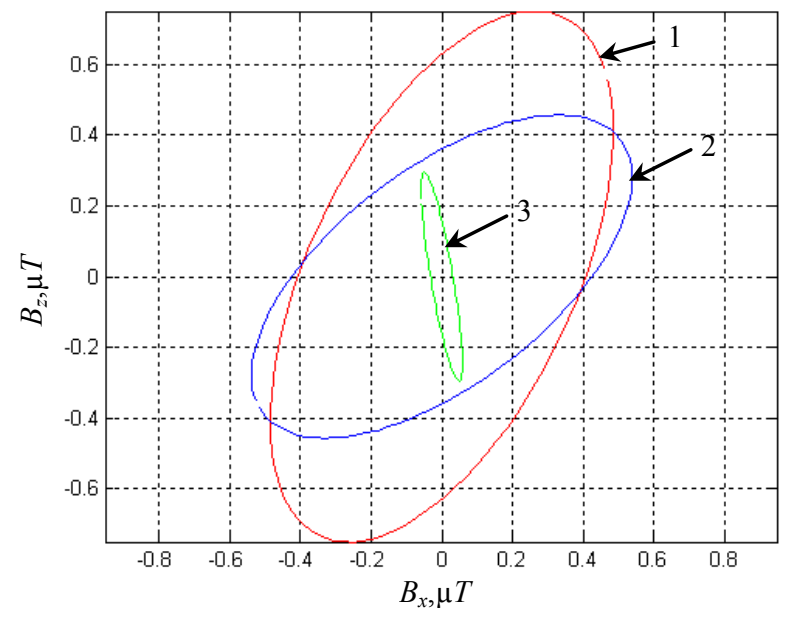

Fig. 18. Comparison of space-time characteristics of magnetic flux density between with and without system of active shielding and both shielding coils

The STC of initial MF generated by OPL with phase conductors triangular arrangements close to the circle. STC of MF generated by both SC is also close to the circle of the STC of initial MF, which ensures high shielding factor.

The STC of the resulting MF generated by OPL and only single $\mathrm{SC}$ is an ellipse, which will be shielded by another SC. In Figure 19 are shown the STC of the initial MF generated by OPL, shielding MF generated by only single first SC and the resulting MF when only single first $\mathrm{SC}$ is used.

As can seen from Fig. 19, the STC of the resulting MF is a strongly elongated ellipse, the semi-major axis of which is almost 1.5 times larger than the STC of the initial MF, and therefore, due to only single first SC work, initial MF is almost twice re compensated. However, then after second SC switching resulting MF STC becomes significantly less than the STC of initial MF, which ensures high shielding factor. Note that the STC of the resulting MF, left after the operation of only single first $\mathrm{SC}$, practically parallel with the STC generated by the MF using only single second SC.

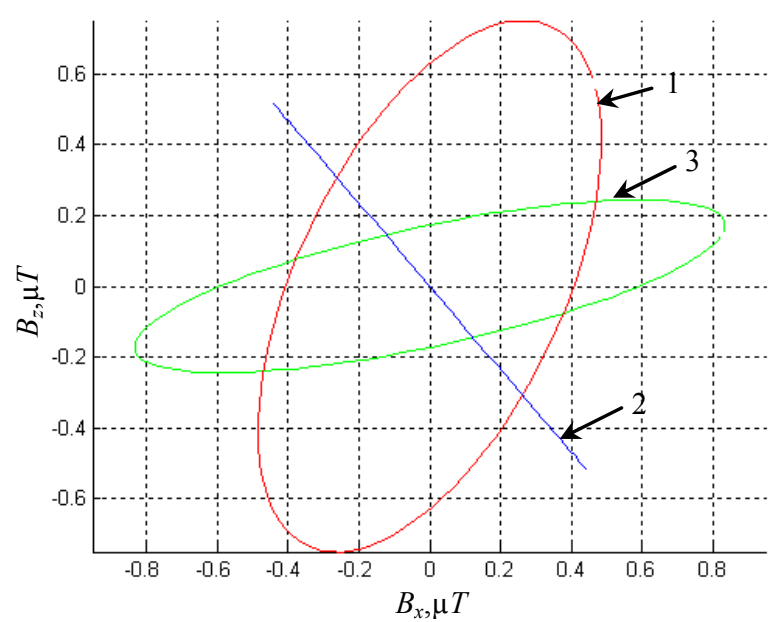

Fig. 19. Comparison between space-time characteristics of magnetic flux density without and with system of active shielding with only single first shielding coil and only single first shielding coil

In Figure 20 are shown the STC of the initial MF generated by OPL, shielding MF generated by only single second $\mathrm{SC}$ and the resulting MF when only single second $\mathrm{SC}$ is used.

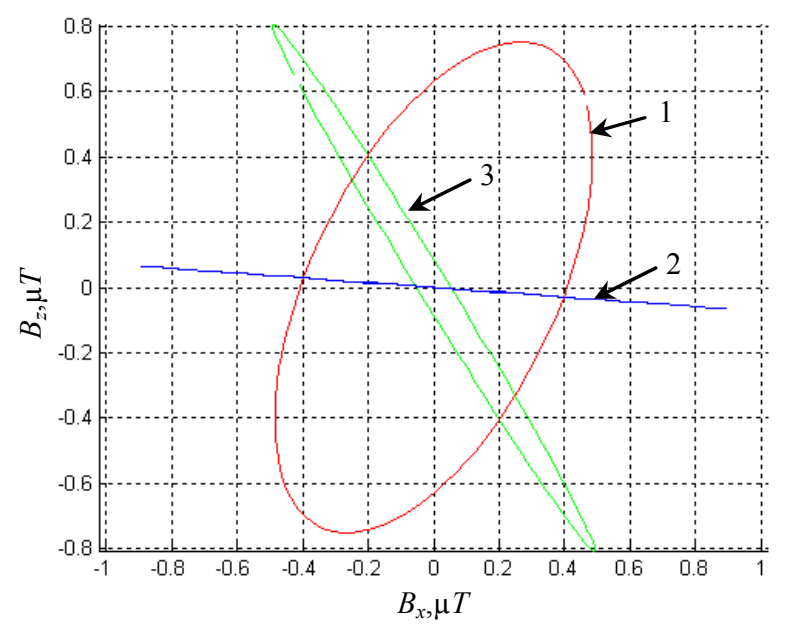

Fig. 20. Comparison between space-time characteristics of magnetic flux density without and with system of active shielding with only single second shielding coil and only single second shielding coil

At 250 A OPL current the initial magnetic flux density level ranges from $0.75 \mu \mathrm{T}$ to $0.33 \mu \mathrm{T}$ in all shielding space, as can be seen from Fig. 17. However, when SAS is on and with only single first SC is used, the magnetic flux density level ranges from $1.5 \mu \mathrm{T}$ to $0.3 \mu \mathrm{T}$ in all shielding space. Consequently, when SAS is on and with only single first $\mathrm{SC}$ is used initial magnetic flux density level more than double due to overcompensation. When SAS is on and with only single second SC is used, the magnetic flux density level ranges from $1.5 \mu \mathrm{T}$ to $0.35 \mu \mathrm{T}$ in all shielding space. Consequently, when SAS is on and with only single second SC is used initial magnetic flux density level also more than double due to recompensation. However, when SAS is on and with both first SC and second SC is used, the magnetic flux density level does not exceed $0.26 \mu \mathrm{T}$ in all shielding space. Consequently, when SAS is on and with both first SC and second SC is used shielding factor is 2.88 . 
Note that with the first variant of the location of the SC shown in Fig. 1 and Fig. 2, magnetic flux density value of the initial MP decreases from $0.75 \mu \mathrm{T}$ to $0.12 \mu \mathrm{T}$ and, therefore, the shielding factor is 6.25 . However, in this case, it is necessary to use 86.2448 AT and 86.2768 AT in a SC. Such a large value of the amperes turns in SC are due to the fact that in this variant the both $\mathrm{SC}$ are located closer to the transmission line, but with the variant of the location of the SC shown in Fig. 16 and Fig. 17, at the same 250 A OPL current, the initial magnetic flux density level are reduced from $0.75 \mu \mathrm{T}$ to $0.26 \mu \mathrm{T}$ and, therefore, the screening factor is 2.88 . However, in this case, it is necessary to use 28.7127 AT and 25.6121 AT in a SC. Such a small value of the amperes turns in SC is because in this variant the both $\mathrm{SC}$ are located far from OPL.

Experimental research. Consider the field experimental research of the SAS model. SC upper parts of SC located at heights of $2.9 \mathrm{~m}$ and $3.2 \mathrm{~m}$ from the ground, and the SC lower parts located at heights of $1 \mathrm{~m}$ and $0.1 \mathrm{~m}$ from the ground. Both SC contains 20 winds and are powered by $1.4 \mathrm{~A}$ and $1.25 \mathrm{~A}$ current from amplifier type TDA7294. In Figure 17 are shown comparison of magnetic flux density between measurements (cross) and simulations (solid) with and without SAS. The experimental SAS shielding factor is also more than 2 units. A magnetic flux density difference between measurements and simulations in the shielding zone does not exceed $20 \%$.

\section{Conclusions.}

1. For the first time the synthesis, computer modeling and field experimental research of the effectiveness of system of active shielding of magnetic field with circular space-time characteristic, generated by overhead power lines with triangular conductor's arrangement, and with different shielding coils spatial positions are given.

2. The synthesis of two degree of freedom robust two-circuit system of active shielding is based on multicriteria stochastic game decision, which is calculated by multiswarm stochastic multi-agent optimization from Pareto-optimal solutions. Multi-criteria game vector payoff is calculated based on the Maxwell equations solution. The spatial arrangement and currents in two shielding coils, the regulator parameters and resulting magnetic flux density value in the shielding space are determined by the system synthesis.

3. It was found, that depending on the shielding coils spatial positions, the shielding factor level varies in the range from 6.25 to 2.88 . The closer the shielding coils are located to overhead power lines, the shielding factor level higher. However, the closer the shielding coils are located to overhead power lines, it is necessary the amperes of turns greater in shielding coils by shield the initial magnetic field in the shielding space. Naturally, with the same shielding coils arrangement when the overhead power line current changes, the shielding coils current changes in proportion to the line current.

4. It is shown, that when only single first shielding coil or only single second shielding coil is working separately, the initial magnetic flux density level may increases 2-3 times due to overcompensation by initial magnetic field. Moreover, the space-time characteristic of magnetic field, generated separately by only single first shielding coil or only single second shielding coils are straight lines. However the space-time characteristic of the resulting magnetic field, which left after the work of only single first (or second) shielding coil, practically parallel with the space-time characteristic of magnetic field generated by using only single second (or first) shielding coil. It is the space-time characteristic arrangement that provides ensures high shielding factor, when both shielding coils work simultaneously.

5. Based on field experimental research of two degree of freedom robust two-circuits system of active shielding of magnetic field with circular space-time characteristic, generated by overhead power lines with «triangle» type of phase conductor's arrangements, and with different shielding coils spatial positions are shown that experimental and calculated magnetic flux density values in the shielding space spread does not exceed $20 \%$.

\section{REFERENCES}

1. Rozov V., Grinchenko V. Simulation and analysis of power frequency electromagnetic field in buildings closed to overhead lines. 2017 IEEE First Ukraine Conference on Electrical and Computer Engineering (UKRCON). Kyiv, Ukraine, pp. 500-503. doi: 10.1109/UKRCON.2017.8100538.

2. Rozov V.Yu., Grinchenko V.S., Yerisov A.V., Dobrodeyev P.N. Efficient shielding of three-phase cable line magnetic field by passive loop under limited thermal effect on power cables. Electrical engineering \& electromechanics, 2019, no.6, pp. 5054. doi: 10.20998/2074-272X.2019.6.07.

3. Active Magnetic Shielding (Field Cancellation). Available at: http://www.emfservices.com/afcs.html (accessed 12 September 2019).

4. Rozov V.Yu., Reutskyi S.Yu., Pelevin D.Ye., Pyliugina $\mathrm{O}$.Yu. The magnetic field of transmission lines and the methods of its mitigation to a safe level. Technical Electrodynamics, 2013, no. 2, pp. 3-9. (Rus).

5. Rozov V.Yu., Reutskyi S.Yu. Pyliugina O.Yu. The method of calculation of the magnetic field of three-phase power lines. Technical electrodynamics, 2014, no.5, pp. 11-13. (Rus).

6. Salceanu A., Paulet M., Alistar B.D., Asiminicesei O. Upon the contribution of image currents on the magnetic fields generated by overhead power lines. 2019 International Conference on Electromechanical and Energy Systems (SIELMEN). 2019. doi: 10.1109/sielmen.2019.8905880.

7. Bravo-Rodríguez J., Del-Pino-López J., Cruz-Romero P. A Survey on Optimization Techniques Applied to Magnetic Field Mitigation in Power Systems. Energies, 2019, vol.12, no.7, p. 1332. doi: 10.3390/en12071332.

8. Canova A., Giaccone L., Cirimele V. Active and passive shield for aerial power lines. 25th International Conference on Electricity Distribution Madrid, 3-6 June 2019. Paper no. 1096, pp. 1-5.

9. Chorna O., Chornyi O., Tytiuk V. Identification of changes in the parameters of induction motors during monitoring by measuring the induction of a magnetic field on the stator surface. 2019 IEEE International Conference on Modern Electrical and Energy Systems (MEES). Kremenchuk, 2019. doi: 10.1109/MEES.2019.8896554.

10. Chystiakov P., Chornyi O., Zhautikov B., Sivyakova G. Remote control of electromechanical systems based on computer simulators. 2017 International Conference on Modern Electrical and Energy Systems (MEES). Nov. 2017. doi: 10.1109/mees.2017.8248934. 
11. Shenkman A., Sonkin N., Kamensky V. Active protection from electromagnetic field hazards of a high voltage power line. HAIT Journal of Science and Engineering. Series B: Applied Sciences and Engineering, Vol. 2, Issues 1-2, pp. 254-265.

12. Korol S., Buryan S., Pushkar M., Ostroverkhov M. Investigation the maximal values of flux and stator current of autonomous induction generator. 2017 IEEE First Ukraine Conference on Electrical and Computer Engineering (UKRCON), May 2017. doi: 10.1109/ukrcon.2017.8100302. 13. Ostroverkhov M., Buryk M. Control of permanent magnet synchronous motor under conditions of parametric uncertainty. 2019 IEEE International Conference on Modern Electrical and Energy Systems (MEES), Sep. 2019. doi: 10.1109/mees.2019.8896635.

14. Ostroverkhov M., Pyzhov V., Korol S. Control of the electric drive under conditions of parametric uncertainty and coordinates' interrelation. 2017 International Conference on Modern Electrical and Energy Systems (MEES), Nov 2017. doi: 10.1109/mees.2017.8248953.

15. Panchenko V.V., Maslii A.S., Pomazan D.P., Buriakovskyi S.G. Determination of pulsation factors of the system of suppression of interfering harmonics of a semiconductor converter. Electrical engineering \& electromechanics, 2018, no.4, pp. 24-28. doi: 10.20998/2074-272X.2018.4.04.

16. Buriakovskyi S.G., Maslii A.S., Panchenko V.V., Pomazan D.P., Denis I.V. The research of the operation modes of the diesel locomotive CHME3 on the imitation model. Electrical engineering \& electromechanics, 2018, no.2, pp. 59-62. doi: 10.20998/2074-272X.2018.2.10.

17. Buriakovskyi S., Maslii A., Maslii A. Determining parameters of electric drive of a sleeper-type turnout based on electromagnet and linear inductor electric motor. EasternEuropean Journal of Enterprise Technologies, 2016, vol.4, no.1(82), pp. 32-41. (Rus). doi: 10.15587/17294061.2016.75860.

18. Shchur I., Klymko V. Comparison of different types of electromechanical systems for creating of counter-rotating VAWT. 2017 IEEE First Ukraine Conf. on Electrical and Computer Engineering (UKRCON-2017), pp. 373-378. doi: 10.1109/ukrcon.2017.8100513

19. Shchur I. Impact of nonsinusoidalness on efficiency of alternative electricity generation systems. 2010 International School on Nonsinusoidal Currents and Compensation, Lagow, 2010, pp. 218-223. doi: 10.1109/isncc.2010.5524483.

20. Zagirnyak M., Bisikalo O., Chorna O., Chornyi O. A model of the assessment of an induction motor condition and operation life, based on the measurement of the external magnetic field. 2018 IEEE 3rd International Conference on Intelligent Energy and Power Systems (IEPS). 2018. pp. 316-321. doi: 10.1109/ieps.2018.8559564.

21. Zagirnyak M., Chornyi O., Nykyforov V., Sakun O., Panchenko K. Experimental research of electromechanical and biological systems compatibility. Przeglad Elektrotechniczny, 2016, vol.1, no.1, pp. 130-133. doi: 10.15199/48.2016.01.31 22. Zagirnyak M., Serhiienko S., Chornyi O. Innovative technologies in laboratory workshop for students of technical specialties. 2017 IEEE First Ukraine Conference on Electrical and Computer Engineering (UKRCON), May 2017. doi: 10.1109/ukrcon.2017.8100446.
23. Sushchenko O.A., Tunik A.A. Robust optimization of the inertially stabilized platforms. 2012 2nd International Conference "Methods and Systems of Navigation and Motion Control» (MSNMC), Kiev, 2012, pp. 101-105. doi: 10.1109/msnmc.2012.6475102.

24. Sushchenko O.A. Robust control of angular motion of platform with payload based on Hoo-synthesis. Journal of Automation and Information Sciences, 2016, vol. 48, no. 12, pp. 13-26. doi: 10.1615/jautomatinfscien.v48.i12.20.

25. Sushchenko O.A. Robust control of platforms with instrumentation. 2019 IEEE 2nd Ukraine Conference on Electrical and Computer Engineering (UKRCON), Lviv, Ukraine, 2019, pp. 518-521. doi: 10.1109/ukrcon.2019.8879969.

26. Zhiteckii L.S., Azarskov V.N., Solovchuk K.Y., Sushchenko O.A. Discrete-time robust steady-state control of nonlinear multivariable systems: a unified approach. IFAC Proceedings Volumes, 2014, vol. 47, no. 3, pp. 8140-8145. doi: 10.3182/20140824-6-za-1003.01985.

27. Zhiteckii L.S., Solovchuk K.Y. Robust adaptive pseudoinverse model-based control of an uncertain SIMO memoryless system with bounded disturbances. 2019 IEEE 2nd Ukraine Conference on Electrical and Computer Engineering (UKRCON), Lviv, Ukraine, 2019, pp. 621-627. doi: 10.1109/ukrcon.2019.8879824.

28. Electrical installation regulations. 5 th ed. The Ministry of Energy and Coal Mining of Ukraine, 2014. 277 p. (Ukr).

29. Ren Z., Pham M.-T., Koh C.S. Robust Global Optimization of Electromagnetic Devices With Uncertain Design Parameters: Comparison of the Worst Case Optimization Methods and Multiobjective Optimization Approach Using Gradient Index. IEEE Transactions on Magnetics, 2013, vol.49, no.2, pp. 851859. doi: 10.1109/tmag.2012.2212713.

30. Galchenko V.Y., Yakimov A.N. A turmitobionic method for the solution of magnetic defectometry problems in structuralparametric optimization formulation. Russian Journal of Nondestructive Testing, 2014, vol.50, no.2, pp. 59-71. doi: 10.1134/s106183091402003x.

31. Gal'chenko V.Y., Yakimov A.N., Ostapushchenko D.L. Pareto-optimal parametric synthesis of axisymmetric magnetic systems with allowance for nonlinear properties of the ferromagnet. Technical Physics, 2012, vol.57, no.7, pp. 893899. doi: 10.1134/s1063784212070110.

32. Ummels M. Stochastic Multiplayer Games Theory and Algorithms. Amsterdam University Press, 2010. 174 p.

Received 23.12.2019

B.I. Kuznetsov ${ }^{1}$, Doctor of Technical Science, Professor,

T.B. Nikitina ${ }^{2}$, Doctor of Technical Science, Professor,

I.V. Bovdui ${ }^{1}$, Candidate of Technical Science,

${ }^{1}$ State Institution «Institute of Technical Problems of Magnetism of the NAS of Ukraine»,

19, Industrialna Str., Kharkiv, 61106, Ukraine, phone +380505766900 ,

e-mail: kuznetsov.boris.i@gmail.com

${ }^{2}$ Kharkov National Automobile and Highway University, 25, Yaroslava Mudroho Str., Kharkov, 61002, Ukraine, e-mail: tatjana55555@gmail.com

How to cite this article:

Kuznetsov B.I., Nikitina T.B., Bovdui I.V. The effectiveness of active shielding of magnetic field with circular spacetime characteristic and with different shielding coils spatial positions. Electrical engineering \& electromechanics, 2020, no. 3, pp. 15-23. doi: 10.20998/2074-272X.2020.3.03. 